\title{
Educational and behavioural problems in babies of 32-35 weeks gestation
}

\author{
C L J Huddy, A Johnson, P L Hope
}

\begin{abstract}
Aim-To identify incidence of school and behaviour problems at age 7 years in children born between 32 and 35 weeks gestation, and investigate perinatal risk factors. Method-The study population consisted of all children born at 32-35 weeks gestation to mothers resident in Oxfordshire in 1990. General practitioners, parents, and teachers were asked about health, behaviour, and education by postal questionnaire. Teachers rated children on level of function in six areas using a five point scale. They also completed the Strengths and Difficulties behaviour questionnaire. Perinatal risk factors were identified for children with poor school performance using a univariate and multivariate analysis.
\end{abstract}

Results-Teacher responses were obtained for $117(66 \%)$ of the 176 children in the cohort. Twenty nine $(25 \%)$ required support from a non-teaching assistant, five $(4 \%)$ had required a statement of special educational needs, and three (3\%) were at special school. Poor outcome was reported for $32 \%$ in writing, $31 \%$ in fine motor skills, $29 \%$ in mathematics, $19 \%$ in speaking, $21 \%$ in reading, and $12 \%$ in physical education. On the behaviour questionnaire, $19 \%$ of the cohort achieved an abnormal hyperactivity score (population norm $10 \%$ ). Multivariate analysis showed perinatal variables that remained significant, independent of other variables; they were discharge from the special care baby unit $>36$ weeks postconceptional age (odds ratio $4.15 ; 95 \%$ confidence interval 1.43 to 12.05 ) and male sex (odds ratio $3.88 ; 95 \%$ confidence interval 1.42 to 10.6).

Conclusion-Up to a third of children born between 32 and 35 weeks gestation may have school problems. As there are larger numbers in this gestational category compared with smaller babies, this finding has implications for educational services.

(Arch Dis Child Fetal Neonatal Ed 2001;85:F23-F28)

Keywords: preterm; behaviour; education; follow up study; risk factors

National Perinatal Epidemiology Unit, Institute of Health

Sciences, Old Road, Oxford OX3 7LF, UK A Johnson

Correspondence to: Dr Huddy

huddy@doctors.org.uk

Accepted 16 January 2001
( $<32$ weeks gestation) have been widely reported. ${ }^{2-7}$ More subtle long term morbidities have been identified, including difficulties in areas of learning and academic achievement, visuomotor integration, and language skills. ${ }^{7-9}$ Minor developmental abnormalities, motor delay, and behavioural problems have also been noted. ${ }^{5}{ }^{10-14}$ There is relatively little information, however, about the longer term outcome of larger preterm babies, born between 32 and 35 weeks gestation. Most of these babies survive, many with an uncomplicated neonatal period. They are generally considered to be at low risk of later neurodevelopmental problems and are not usually followed up. Apart from those with obvious serious motor or sensory disorders, most are placed in normal mainstream school and are assumed to have a good outcome, not differing from their term peers. Although many of these children do well, information from large population studies and registers of impairment and disability, such as cerebral palsy registers, indicate that babies born between 32 and 35 weeks gestation do have a higher incidence of later problems than babies born at term. ${ }^{15-17}$ As the number of surviving children in this intermediate gestational age group is much higher than the number of surviving babies born before 32 weeks gestation, even a modest increase in the risk of preschool or school difficulties will have considerable resource implications, as well as being important for parents and children themselves.

Previous studies of outcome at school age in children born very preterm have tended to be small, used a wide range of psychometric methods, and, in general, have been based on a highly selected population attending a tertiary centre. $^{239}$ We decided to explore a different methodology, using a simple, inexpensive questionnaire method of follow up on a relatively large sample, in order to ascertain the extent of school problems in a geographically defined cohort of children born between 32 and 35 weeks gestation.

Risk factors for adverse school outcome in this group of larger preterm babies are unknown. As many of these babies have an uncomplicated intrapartum and neonatal period, it seems possible that adverse factors in the antenatal period may play an important role in determining outcome. We decided to investigate this by using information from a routinely collected maternity dataset and from maternal and infant medical records. We compared the incidence of antenatal, intrapartum, and neonatal factors in children with an adverse school outcome with those who did not have school problems. 


\section{Methods}

This is a case-control study nested in a birth cohort. The cohort consisted of all children born during the year 1990 with gestations 32-35 completed weeks to mothers resident in the Oxfordshire district at the time of delivery. Information for most of these was available from OXMAT, a computerised system that records details of all births in the John Radcliffe Hospital. Other births included in the cohort were selected by searching delivery records for the Horton General Hospital, Banbury, community hospitals, and records of all home births. Deliveries to US military personnel in the Upper Heyford US airforce base were excluded. Babies born outside the boundaries but resident in Oxfordshire were located from the community child health service and are included in the study.

Gestational age was verified by mother's last menstrual period, if certain and agreeing within two weeks of ultrasound, or by ultrasound if not. If neither of these were known, gestation according to paediatric assessment was used.

Once the babies were identified, a letter was sent to the families' general practitioners asking them to give permission for us to send a questionnaire to the parents, unless they thought it inappropriate, and return a receipt to us. The general practitioners were asked for basic information about the status of each child.

A questionnaire was sent to the parents with a covering letter explaining the purpose of the project. They were asked to complete and return the questionnaire and give consent for the child's teacher to be contacted. Further questionnaires were then sent directly to the child's school. We informed the parents that a copy of the teacher's report would be made available to them if they wished. This method has been validated and used before for developmental follow up studies. ${ }^{18}$

The questionnaire sent to the parents included questions on health, development, education, and behaviour. It was expected that major disabilities such as cerebral palsy, visual impairment, sensorineural hearing loss, and severe developmental delay would be identified from responses made by parents.

The teachers were asked for information about any additional help the child was receiving at school. They were asked to rate the children on their level of function in six areasspeaking/listening, writing/composition, fine motor skills, mathematics, reading, and physical education - using a five point scale. On this scale a score of 1 indicated good ability, a score of 3 indicated average ability, and a score of 5 indicated very poor ability. The child would be considered to have difficulty in a particular skill if the rating was 4 or 5 . The teachers were also asked to complete the Strengths and Difficulties behaviour questionnaire (SDQ). ${ }^{19}$ This behaviour questionnaire has five scales covering conduct problems, hyperactivity, emotional symptoms, peer problems, and prosocial behaviour. All but the last can be summed to generate a total problem score. In the standardisation of the behaviour questionnaire, cut off points were selected within each of the subscales so that about $80 \%$ of children in the community are normal, $10 \%$ are borderline, and $10 \%$ are abnormal. ${ }^{19}$ School problems in children were defined as those who had (a) a score of more than 3 in a skill area as assessed by teachers, $(b)$ a requirement for non-teaching assisted support, or (c) a borderline or abnormal result on the SDQ. The analysis focused on whether school problems were related to gestational age at birth. We also noted whether health service use was related to gestational age.

Secondary tracing methods were used to find families who could not be traced, through community records, the Family Health Service Authority (FHSA), and the National Health Service Central Register (NHSCR). Those who did not respond to the initial correspondence were sent a second questionnaire. General practitioners and teachers (but not parents) were contacted once by telephone if necessary.

Maternal and neonatal notes were examined in order to collect information on possible antenatal, perinatal, and postnatal risk factors. This information was collected blind to the seven year outcome. To identify perinatal risk factors associated with poor school performance, two children with known abnormalities of chromosome 16 were excluded from the analysis. For this case-control part of the study, we used a high threshold for the definition of school problems. Children with poor school performance were defined as those scoring either 4 or 5 in three or more skill areas, or who were requiring additional help at school (non-teaching assisted support, special schooling, and help as a result of an educational statement). Children who met these criteria were identified as cases and those without poor school performance acted as controls. Results of comparisons of cases and controls were given as odds ratios (OR) with $95 \%$ confidence intervals $(95 \% \mathrm{CI})$. The risk factors were analysed statistically by univariate and multivariate analyses using SPSS for Windows. Definitions of risk factors are listed in the appendix.

Ethical approval for the study was obtained from the central Oxford research ethics committee.

\section{Results}

There were 187 babies born to mothers resident in Oxfordshire in 1990. There were six neonatal deaths (two from congenital diaphragmatic hernia, one each with congenital myotonic dystrophy, Potter's syndrome, congenital heart block, and Down's syndrome with hydrops and pulmonary hypoplasia) and five sudden infant deaths (ages two, three, four, five, and seven months). Five percent of children were lost as a result of movement out of the region. The general practitioner response rate was $95 \%$, parent response rate was $81 \%$, and the teacher response rate was $97 \%$. General practitioners suggested that we did not contact eight children (reasons included poor social circumstances, maternal psychiatric illness, recent bereavement, disabled sibling at home, and a family that preferred alternative 
Table 1 No (\%) children with school problems, as assessed by teachers

\begin{tabular}{|c|c|c|c|c|c|}
\hline & $\begin{array}{l}32-35 \text { weeks } \\
(n=117)\end{array}$ & $\begin{array}{l}32 \text { weeks } \\
(n=12)\end{array}$ & $\begin{array}{l}33 \text { weeks } \\
(n=22)\end{array}$ & $\begin{array}{l}34 \text { weeks } \\
(n=38)\end{array}$ & $\begin{array}{l}35 \text { weeks } \\
(n=45)\end{array}$ \\
\hline Receiving non-teaching assisted help at school & $29(25)$ & $5(42)$ & $4(18)$ & $9(24)$ & $11(24)$ \\
\hline Receiving special school as a result of statementing & $5(4)$ & 1 & 2 & 1 & 1 \\
\hline Attending a special school or class & $3(3)$ & 1 & 1 & 0 & 1 \\
\hline Score $>3$ in speaking $/$ listening & $22(19)$ & $4(33)$ & $3(14)$ & $7(18)$ & $8(18)$ \\
\hline Score $>3$ in writing/composition & $37(32)$ & $6(50)$ & $3(14)$ & $13(34)$ & $15(33)$ \\
\hline Score $>3$ in fine motor skills & $36(31)$ & $6(50)$ & $4(18)$ & $11(29)$ & $15(33)$ \\
\hline Score $>3$ in mathematics & $34(29)$ & $5(42)$ & $5(23)$ & $11(29)$ & $14(31)$ \\
\hline Score $>3$ in reading & $25(21)$ & $3(25)$ & $4(18)$ & $8(21)$ & $10(22)$ \\
\hline Score $>3$ in physical education & $14(12)$ & $4(33)$ & $3(14)$ & $3(8)$ & $4(9)$ \\
\hline
\end{tabular}

Proportion of all children receiving statement of special educational needs in Oxfordshire, $1.74 \%$.

treatments). Three parents replied but did not wish to answer the questionnaire, and one child was educated at home. Of the 176 eligible for follow up, there were 135 singletons, 38 twins, and three triplets. The mean gestational age was 241 days (34.3 weeks) and the median birth weight $2180 \mathrm{~g}$ (range 1060-4200). There were 80 girls and 96 boys. A total of 147 were admitted to special care baby units, 26 were managed on postnatal wards, and this information was unavailable for three. The median maternal age was 27 years, and $89 \%$ of the mothers and $88 \%$ of the fathers were caucasian. Within the cohort of survivors were 16 babies with congenital abnormalities. Two twins had an abnormality of chromosome 16 which they inherited from their mother; both required statements of special educational needs and received non-teaching assisted help. Seven children had forms of congenital heart disease, one had a unilateral pelviureteric junction obstruction, and one had panhypopituitarism. Five children had very mild abnormalities (inguinal hernia, accessory digit, imperforate hymen) and two had pre-auricular skin tags.

Among the babies whose parents and teachers did not respond, there was a higher proportion of 32 week gestation babies $(20.4 \%$ $v 10.3 \%)$ and a higher percentage of multiple births (31\% v 19.7\%). Among those for whom the information was available, there was a higher percentage of social class I and II among responders to the parents' questionnaires compared with non-responders $(29.6 \% v 38.5 \%)$.

Parents reported $17 \%(21 / 122)$ of the children in the study as having visited hospital outpatients in the previous year, and 10\% (12/ 122) had been inpatients for various reasons including respiratory, surgical, and endocrine problems. In all, $70 \%(85 / 122)$ of the children had visited their general practitioner in the previous year. There was no relation between health service use and gestation. Within the whole group, one child had been to a physiotherapist within the last year, five to speech therapists, 15 to eye specialists, one to a psychologist, and four to hearing specialists.

Table 1 shows the numbers of children with problems at school as assessed by teachers. The most common form of additional help needed at school was non-teaching assisted help in $25 \%$. The proportion of children receiving help as a result of statementing was $4 \%$. The overall proportion of children statemented in Oxfordshire is $1.7 \%$. Almost one third of children in this cohort were identified as having school problems by scoring 4 or 5 in writing, fine motor skills, and mathematics, but there was no significant trend across the gestational age groups ( $\chi^{2}$ for trend not significant).

Tables 2 and 3 show the number of children with normal, borderline, and abnormal behaviour as assessed by the SDQ and reported by parents and teachers. Questionnaires completed by parents and teachers show $18.0 \%$ and $18.8 \%$ respectively of children scoring abnormally for hyperactivity. This did not appear to be related to gestational age $(8.8 \%$ of 32 weeks, $21.7 \%$ of 33 weeks, $15.8 \%$ of 34 weeks, and $21.7 \%$ of 35 weeks). Overall 34 children $(27.9 \%)$ were assessed as being hyperactive by either parent or teacher. However, only $10(8 \%)$ children were assessed as being hyperactive by both. Hyperactivity as reported by both parents and teachers was associated with poor school performance: OR 3.04 (95\% CI 1.07 to 8.63) and OR 5.47 (95\% CI 1.94 to 15.4 ) respectively.

Table 4 shows social risk factors for poor school performance. Maternal smoking showed a significant relation to outcome, whereas marital status, maternal age, racial origin, social class, and maternal education did not. Table 5 shows antenatal and perinatal risk factors for poor school performance. Multiparity, severe pre-eclamptic toxaemia, and interventional delivery had a significant association. There was no obvious effect of pre-eclampsia that was not severe, antepartum haemorrhage, prolonged rupture of membranes, multiple pregnancy, or acidosis at birth. Table 6 gives postnatal risk factors. Only nine babies in the cohort were ventilated, and this was not a

Table 2 No (\%) children having behaviour problems as reported by parents $(n=122)$

\begin{tabular}{llll}
\hline & Normal & Borderline & Abnormal \\
\hline Total difficulties score & $93(76.2)$ & $14(11.4)$ & $13(10.6)$ \\
Emotional symptoms score & $95(77.8)$ & $13(10.6)$ & $12(9.8)$ \\
Conduct problems score & $91(74.6)$ & $16(13.1)$ & $13(10.6)$ \\
Hyperactivity score & $89(72.9)$ & $9(7.4)$ & $22(18.0)$ \\
Peer problems score & $93(76.2)$ & $13(10.7)$ & $14(11.5)$ \\
Prosocial behaviour score & $105(86.1)$ & $8(6.6)$ & $7(5.7)$ \\
\hline
\end{tabular}

Table 3 No (\%) children having behaviour problems as reported by teachers $(n=117)$

\begin{tabular}{llll}
\hline & Normal & Borderline & Abnormal \\
\hline Total difficulties score & $91(77.7)$ & $15(12.8)$ & $11(9.4)$ \\
Emotional symptoms score & $100(85.4)$ & $10(8.5)$ & $7(6.0)$ \\
Conduct problems score & $107(91.4)$ & $5(4.3)$ & $5(4.3)$ \\
Hyperactivity score & $91(77.7)$ & $4(3.4)$ & $22(18.8)$ \\
Peer problems score & $103(88.0)$ & $6(5.1)$ & $8(6.8)$ \\
Prosocial behaviour score & $91(77.7)$ & $11(9.4)$ & $15(12.8)$ \\
\hline
\end{tabular}


Table 4 Social risk factors for poor school performance

\begin{tabular}{llll}
\hline Risk factor & $\begin{array}{l}\text { No }(\%) \text { cases } \\
(n=34)\end{array}$ & $\begin{array}{l}\text { No(\%) controls } \\
(n=80)\end{array}$ & $\begin{array}{l}\text { Odds ratio } \\
\text { (95\% CI) }\end{array}$ \\
\hline Unmarried mother & $7(20.6)$ & $14(17.5)$ & $1.22(0.4$ to 3.4) \\
Maternal smoking & $15(44.1)$ & $17 / 75(22.7)$ & $2.69(1.1$ to 6.4) \\
Maternal age $\geqslant 35$ years & $5(14.7)$ & $6(7.5)$ & $2.13(0.6$ to 7.5$)$ \\
Non-white mother & $2 / 32(6.2)$ & $4 / 73(5.5)$ & $1.15(0.2$ to 6.6$)$ \\
Social class IV to $V^{\star}$ & $3 / 33(9.1)$ & $11 / 74(14.9)$ & $0.57(0.1$ to 2.2$)$ \\
No maternal education after 16 years age & $18(52.9)$ & $37 / 78(47.4)$ & $1.25(0.6$ to 2.8$)$ \\
\hline
\end{tabular}

^Data not available for some babies.

Table 5 Antenatal and perinatal risk factors for poor school performance

\begin{tabular}{|c|c|c|c|}
\hline Risk factor & $\begin{array}{l}\text { No (\%) cases } \\
(n=34)\end{array}$ & $\begin{array}{l}\text { No }(\%) \\
\text { controls }(n=80)\end{array}$ & $\begin{array}{l}\text { Odds ratio } \\
\text { (95\% CI) }\end{array}$ \\
\hline Multiparity* & $20(58.8)$ & $30 / 79(40.0)$ & $2.33(1.0$ to 5.3$)$ \\
\hline Induced conception ${ }^{\star}$ & $4 / 33(12.1)$ & $9 / 76(11.8)$ & $1.03(0.29$ to 3.6$)$ \\
\hline Pre-eclamptic toxaemia (PET) & $8(23.5)$ & $14(17.5)$ & $1.45(0.5$ to 3.9$)$ \\
\hline Severe PET & $7(20.6)$ & $5(6.2)$ & $3.9(1.1$ to 13.3$)$ \\
\hline History of antepartum haemorrhage (APH) & $11(32.3)$ & $24 / 79(30.3)$ & $1.1(0.5$ to 2.6$)$ \\
\hline APH $<20$ weeks $\star$ & $8(23.5)$ & $10 / 78(12.8)$ & $2.09(0.7$ to 5.9$)$ \\
\hline Prolonged rupture of membranes ${ }^{\star}$ & $5(14.7)$ & $13 / 78(16.7)$ & $0.86(0.3$ to 2.6$)$ \\
\hline Multiple pregnancy & $7(20.6)$ & $14(17.5)$ & $1.22(0.4$ to 3.4$)$ \\
\hline Non-cephalic presentation & $8(23.5)$ & $11(13.8)$ & $1.93(0.7$ to 5.3$)$ \\
\hline Interventional delivery & $23(67.6)$ & $35(43.8)$ & $2.69(1.2$ to 6.3$)$ \\
\hline Cord arterial gas $<7.25^{\star}$ & $10 / 21(47.6)$ & $25 / 51(49.0)$ & $0.95(0.3$ to 2.6$)$ \\
\hline Cord arterial gas $<7.1^{\star}$ & $2 / 21(9.5)$ & $4 / 51(7.8)$ & $1.2(0.2$ to 7.3$)$ \\
\hline
\end{tabular}

$\star$ Data not available for some babies.

Table 6 Neonatal risk factors for poor school performance

\begin{tabular}{|c|c|c|c|}
\hline Risk factor & $\begin{array}{l}\text { No (\%) cases } \\
(n=34)\end{array}$ & $\begin{array}{l}\text { No }(\%) \text { controls } \\
(n=80)\end{array}$ & $\begin{array}{l}\text { Odds ratio } \\
(95 \% \mathrm{CI})\end{array}$ \\
\hline Sex male & $25(73.5)$ & $36(45.0)$ & $3.4(1.4$ to 8.2$)$ \\
\hline Intrauterine growth retardation & $9(26.5)$ & $17(21.1)$ & $1.3(0.5$ to 3.4$)$ \\
\hline Respiratory illness & $19(55.9)$ & $24(30)$ & $3.0(1.3$ to 6.8$)$ \\
\hline Ventilation & $3(8.8)$ & $6(7.5)$ & $1.2(0.3$ to 5.1$)$ \\
\hline Oxygen treatment & $16(47.1)$ & $19(23.8)$ & $2.9(1.2$ to 6.7$)$ \\
\hline Maximum SBR $>250^{\star}$ & $4 / 33(12.1)$ & $11 / 71(15.5)$ & $0.8(0.2$ to 2.6$)$ \\
\hline Hypothermia ${ }^{\star}$ & $10 / 33(30.3)$ & $18 / 79(22.8)$ & $1.5(0.6$ to 3.7$)$ \\
\hline Hypoglycaemia ${ }^{\star}$ & $12 / 18(66.7)$ & $23 / 44(52.3)$ & $1.8(0.6$ to 5.7$)$ \\
\hline Breast fed on discharge ${ }^{\star}$ & $11(32.3)$ & $30 / 79(38.0)$ & $0.8(0.3$ to 1.8$)$ \\
\hline $\begin{array}{l}\text { Discharged from SCBU }>36 \text { weeks } \\
\text { corrected age }\end{array}$ & $25 / 32(78.1)$ & $33 / 61(54.1)$ & $3.0(1.1$ to 8.06$)$ \\
\hline
\end{tabular}

$\star$ Data not available for some babies.

SCBU, Special care baby unit; SBR, serum bilirubin.

significant risk factor for poor outcome. However, the presence of respiratory illness and oxygen treatment showed a significant association. Male sex and a prolonged admission, which we arbitrarily defined as discharge from the neonatal unit at greater than 36 weeks postconceptual age, were also significantly related to poor school performance. Intrauterine growth retardation, hypothermia, hypoglycaemia, and hyperbilirubinaemia were not significant. Male sex is a risk factor particularly for problems with speech (RR 5.02; CI 1.55 to $16.2 ; \mathrm{p}<0.01$ ), reading ( $R R$ 2.08; CI 1.21 to $6.5 ; \mathrm{p}<0.01$ ), fine motor skills (RR 2.88; CI 1.42 to $5.81 ; \mathrm{p}<0.001)$, and writing/ composition (RR 2.3; CI 1.22 to 4.32 ; $<<0.01$ ) but not mathematical skills (RR 1.12; CI 0.617 to $2.02 ; \mathrm{p}<0.8)$. Male sex was also a risk factor for teachers' reporting of hyperactivity (OR $4.64 ; 95 \%$ CI 1.42 to 15.2 ), but not for parents' reporting (OR 1.8; 95\% CI 0.63 to 5.17). Maternal age of 35 years or above was a significant risk factor for poor reading ( $R R$ 2.36; CI 1.11 to 5.04 ; $\mathrm{p}<0.05$ ).

Interactions of risk factors were investigated by entering variables into a logistic regression model. Variables that remained significant, independent of other variables, were discharge from the special baby care unit $>36$ weeks corrected age (OR $4.1 ; 95 \%$ CI 1.4 to 12.0 ) and male sex (OR 3.9; 95\% CI 1.4 to 10.6). If discharge from the special baby care unit was removed from the model, the significant variables were respiratory illness (OR 3.1; 95\% CI 1.3 to 7.7 ), male sex (OR 3.7; 95\% CI 1.4 to 9.3), and interventional delivery (OR 2.6; $95 \%$ CI 1.0 to 6.5 ).

Univariate analysis showed that babies discharged beyond 36 weeks postconceptual age were more likely to be growth retarded (OR $6.3 ; 95 \%$ CI 1.7 to 23.2 ), to be female (OR 2.8; $95 \% \mathrm{CI} 1.1$ to 6.8 ), and to have had respiratory illness (OR 2.6; 95\% CI 1.0 to 6.2) than those discharged before 36 weeks postconceptual age.

\section{Discussion}

We have tested a simple postal questionnaire method of ascertaining the school performance of children born between 32 and 35 weeks gestation. Although non-response is always a problem in such methods, the questionnaire response rate in this study compares well to other postal surveys. ${ }^{20}$ In all, $34 \%$ of the sample was lost to follow up, the biggest loss being from parents failing to reply to questionnaires $(16 \%)$. Loss to follow up can cause bias in many ways that mainly underestimate the severity or the frequency of problems. ${ }^{20-23}$ Twin pregnancies and those of the lowest gestation were over-represented in our non-responding group as were babies whose duration of stay on the neonatal unit had been beyond 36 weeks corrected gestation. Therefore the incidence of school problems in this study may be an underestimate. However, teachers may overestimate problems in children once they know that they are part of a study. The advantage of using a questionnaire method is that it is relatively inexpensive, easy to use, and can be applied to populations.

Up to a third of children born between 32 and 35 weeks gestation will have some form of school problem. Almost a quarter of children in the study were receiving non-teaching assisted help at school, and $4 \%$ were receiving help as a result of an educational statement. This proportion is similar to that described in a recent geographical study of very low birthweight (VLBW) babies in New Zealand, of whom $22.9 \%$ were receiving special educational assistance, ${ }^{24}$ but less than that described in a Dutch cohort of VLBW babies, where $38 \%$ had special assistance. ${ }^{25}$ Direct comparison with other studies is limited, however, as different countries vary in their criteria for deciding which children need help. A study performed in the United Kingdom by Middle et $a l^{20}$, who used a very similar method to our own, found that $24.1 \%$ of a cohort of babies $<1500 \mathrm{~g}$ were receiving non-teaching assisted help compared with only $18.7 \%$ of babies $1500-2499 \mathrm{~g}$ and $9.1 \%$ of babies $>2500 \mathrm{~g}$. The results shown here for teacher ratings in fine motor skills and mathematics are similar to those expressed for the 1500-2499 g group in her study, whereas for reading and physical education the results are similar to the $>2500$ g group, ratings for speaking/listening and 
writing/composition lying between her two birth weight groups. We did not study term controls. Other studies using normal population controls suggest that $10-20 \%$ of control children perform below the average range, as assessed by teachers. ${ }^{6}{ }^{25}$ Detailed studies of learning difficulties encountered by children who were born with VLBW have identified many areas in which performance is worse than other children. ${ }^{4-710-12}$ Poor motor skills and ability in children who were low birthweight babies are markers of later learning difficulties and may affect school activities such as writing and physical education. ${ }^{26}$ In this study, $32 \%$ of children had poor handwriting, but only $12 \%$ scored badly in physical education.

The results of both parents' and teachers' questionnaires suggest that an excess of children in this cohort show signs of hyperactivity. Problems within the hyperactivity spectrum, such as difficulty in concentration, have been consistently found in follow up studies of VLBW children, ${ }^{1013}{ }^{14}$ and these have been evident regardless of whether assessments have been made by parents, teachers, or clinicians. Studies comparing rates of hyperactivity in low birthweight infants and controls have given inconsistent results. ${ }^{27} 28$ There is increasing evidence that VLBW children are more likely to suffer a "pure" form of attention deficit disorder which is not associated with the development of conduct disorder, as it is in the general child population. ${ }^{14}$ There was, however, no excess of children in this cohort with conduct disorder and we did show that there is an association between reports of hyperactivity from parents and teachers and poor school performance. This has been reported previously in VLBW populations by Pharoah. ${ }^{13}$

There was poor correlation between the results of the parents' and teachers' questionnaires in this study. Goodman ${ }^{19}$ reports a high intermeasure correlation for each type of behaviour in the SDQ as a whole. It has been recognised that distinctions can be made between "pervasive" hyperactivity manifest in a variety of settings, "school" hyperactivity, and "home" hyperactivity, and the poor correlation between the parents' and teachers' questionnaires may represent the manifestation of hyperactivity in different settings.

Low social class and limited maternal education were not significantly associated with poor school performance, in contrast with previous studies. ${ }^{24}{ }^{29}$ Within the limited gestational age range of this study, outcome was not associated with gestational age, birth weight, or intrauterine growth retardation. Reduced survival and increased rates of severe disability are related to gestation in very preterm infants, but the relation of milder impairments to gestation is less clear. ${ }^{24}{ }^{30}$ Controversy exists as to the relative importance of birth weight and gestational age as risk factors for adverse outcome. ${ }^{31-34}$

Multiple pregnancies were not a significant risk factor in our study, although the numbers were small. Previous studies disagree as to whether multiples are at risk of poorer outcome or not. ${ }^{253235}$ The association of poor school performance with severe pre-eclampsia is interesting. Pre-eclampsia has been shown in some studies of outcome of very preterm $(<32$ weeks) and VLBW infants to be associated with a reduced risk of cerebral palsy. ${ }^{32}{ }^{36}$ Sutton et $a l^{\beta 7}$, who describe the antecedents and outcomes of severe morbidity in New South Wales term infants, however, cite maternal hypertension as a risk factor.

Our study showed an association between poor outcome at school and respiratory illness. This cohort of babies did not have a large number of very sick infants. Only nine of them were ventilated, the remaining 34 with respiratory illness had a milder course requiring continuous positive airways pressure, oxygen treatment, or no additional respiratory support. Discharge beyond 36 weeks corrected age was a marker of poor outcome. This may reflect severity of respiratory illness but also any cause of delayed feeding.

Despite the methodological limitations of this study, it is clear that children of school age who were born at 32-35 weeks gestation have a very significant risk of educational difficulties. The increased risk of problems should be recognised in this very large group of babies as well as the survivors of extreme prematurity.

\section{Appendix}

Pre-eclampsia: the presence of hypertension (diastolic $\mathrm{BP}>90 \mathrm{~mm} \mathrm{Hg}$ ) and proteinuria (with or without accompanying biochemical and haematological changes).

Severe pre-eclampsia: significant proteinuria $(\geqslant 0.3$ $\mathrm{mg} / 24 \mathrm{~h}$ ) or untreated diastolic blood pressure $\geqslant 110$ $\mathrm{mm} \mathrm{Hg}$ or abnormal liver biochemistry or symptomatic pre-eclampsia. Pre-eclampsia leading to eclampsia is included.

Intrauterine growth retardation: birth weight less than 10th centile as defined by Oxford standard percentile charts used for 24-42 week gestation babies.

Antepartum haemorrhage: vaginal bleeding regardless of cause after exclusion of local haemorrhage of genital tract.

Prolonged rupture of membranes: rupture for $>24$ hours duration.

Hypoglycaemia: recorded lowest plasma glucose $<2.6$ $\mathrm{mmol} / 1$. Also included those babies treated for hypoglycaemia with an intravenous infusion or bolus.

Hypothermia: lowest recorded temperature $<36.0^{\circ} \mathrm{C}$

Interventional delivery: any delivery that is not a spontaneous vertex vaginal delivery and includes forceps, ventouse, breech, and lower segment caesarean section.

1 Francis-Williams J, Davies P. Very low birthweight and later intelligence. Dev Med Child Neurol 1974;16:709-28.

2 Aylward GP, Pfeiffer S, Wright A, et al. Outcome studies of low birthweight infants published in the last decade: a meta-analysis. F Pediatr 1989;115:515-20.

3 Ornstein M, Ohlsson A, Edmonds J, et al. Neonatal follow-up of very low birthweight/extremely low birthweight infants to school age: a critical Overview. Acta Paeweight infants to school age:
diatr Scand 1991;80:741-8.

4 The Scottish Low Birthweight Study Group. The Scottish low birthweight study. I. Survival, growth, neuromotor and sensory impairment. Arch Dis Child 1992;67:675-81.

5 The Scottish Low Birthweight Study Group. The Scottish low birthweight study. II. Language attainment, cognitive status, and behavioural problems. Arch Dis Child 1992;67:682-6.

6 Saigal S, Szatmari P, Rosenbaum P, et al. Cognitive abilities and school performance of extremely low birthweight children and matched term controlled children at 8 years: a regional study. $\mathcal{F}$ Pediatr 1991;118:751-60.

7 Pharoah POD, Stevenson CJ, Cooke RWI, et al. Clinical and subclinical deficits at 8 years in a geographically defined cohort of low birthweight infants. Arch Dis Child cohort of low

8 Zubrick S, Macartney H, Stanley F. Hidden handicap in school-age children who received neonatal intensive care. Dev Med Child Neurol 1988;30:145-52. 
9 Hack M, Klein N, Taylor. School-age outcomes of children of extremely low birthweight and low gestational age. of extremely low birthweight
Semin Neonatol 1996;1:277-88.

10 Marlow N, Roberts BL, Cooke RWI. Motor skills in extremely low birthweight children at the age of 6 years. Arch Dis Child 1989;64:839-47.

11 Marlow N, Roberts BL, Cooke RWI. Outcome at 8 years for children with birth weights of $1250 \mathrm{~g}$ or less. Arch Dis Child 1993;68:286-90.

12 Powls A, Botting N, Cooke RWI, et al. Motor impairment in children 12 to 13 years old with a birthweight of less than 1250g. Arch Dis Child Fetal Neonatal Ed 1995;72:F62-6.

13 Pharoah POD, Stevenson CJ, Cooke RWI, et al. Prevalence of behaviour disorders in low birthweight infants. Arch Dis Child Fetal Neonatal Ed 1994;70:271-4.

14 Wolke D. Psychological development of prematurely born children. Arch Dis Child 1998;78:567-70.

15 Kempley S, Diffley F, Ruiz G. Birthweight and special educational needs: effects of an increase in the survival of very low birthweight infants in London. 7 Epidemiol Community Health 1995;49:33-7.

16 Johnson A, King R. A regional register of early childhood impairments: a discussion paper. The Steering Committee of the Oxford Region Child Development Project. Community Medicine 1989;11:353-63.

17 Rantakillo P, Von Wendt L. Prognosis for low birthweight infants up to the age of 14. A population study. Dev Med Child Neurol 1985;27:655-63.

18 Alderdice F, Petty T, Johnson A, et al. The feasibility of using a postal survey method to assess the health and development of 7 year old children of different birth weights. F Epidemiol Community Health 1998;52:439-44.

19 Goodman R. The Strengths and Difficulties questionnaire: a research note. F Child Psychol Psychiatry 1997;38:581-6.

20 Middle C, Johnson A, Alderdice F, et al. Birthweight and health and development at the age of 7 years. Child: Care, Health and Development 1996;22:55-71.

21 Wolke D, Sohne B, Ohrt, et al. Follow-up of preterm children: important to document drop-outs. Lancet children: imp

22 Wariyar UK, Richmond S. Morbidity and preterm delivery: Importance of 100\% follow-up. Lancet 1989;388:387-8.

23 Zinkin PM, Cox CA. Child health clinics and inverse care laws: evidence from longitudinal study of 1878 pre-school children. BMF 1976:2:411-13.

24 Horwood LJ, Mogridge N, Darlow BA. Cognitive, educational and behavioural outcomes at 7 to 8 years in a national very low birthweight cohort. Arch Dis Child Fetal Neonatal Ed 1998;79:F12-20.
25 Hille ETM, Lya Den Ouden A, Bauer L, et al. School performance at nine years of age in very premature and very low birthweight infants: perinatal risk factors and predictors at five years of age. F Pediatr 1994;125:426-34.

26 Johnson A, Townsend P, Yudkin, et al. Functional abilities at age 4 years of children born before 29 weeks of gestation. BMF 1993;306:1715-18.

27 Klebanov PK, Brooks-Gunn J, McCormick MC. Classroom behaviour of very low birthweight elementary school children. Pediatrics 1994;5:700-8

28 McCormick MC, Gortmaker SL, Sobol AM. Very low birthweight children: behaviour problems and school difficulty in a national sample. F Pediatr 1990;117:687-93.

29 Robertson CMT, Etches PC, Kyle JM. Eight-year school performance and growth of preterm, small for gestational age infants: a comparative study with subjects matched for birthweight or for gestational age. $\mathcal{F}$ Pediatr 1990;116:1926.

30 Lagercrantz H. Better born too soon than too small. Lancet 1997;350:1044-5.

31 Yu VYH, Downe L, Astbury J, et al. Perinatal factors and adverse outcome in extremely low birthweight infants. Arch Dis Child 1986;61:554-8.

32 Pena IC, Teberg AJ, Finello KM The premature small-forgestational-age infant during the first year of life: Comparison by birthweight and gestational age. $\mathcal{F}$ Pediatr 1988;113:1066-73.

33 In-Kyung S, Vohr B, Oh W. Growth and neurodevelopmental outcome of very low birthweight infants with intrauterine growth retardation: comparison with controls subjects matched by birthweight and gestational age. 7 Pediatr 1993;123:618-24.

34 Marlow N, Hunt LP, Chiswick ML. Clinical factors associated with adverse outcome for babies weighing $2000 \mathrm{~g}$ or less at birth. Arch Dis Child 1988;63:1131-6.

35 Leonard CL, Piecuch RE, Roberta A, et al. Outcome of very low birth weight infants: multiple gestation versus singletons. Pediatrics 1994;93:611-15.

36 Murphy DJ, Hope PL, Johnson A. Neonatal risk factors for cerebral palsy in very preterm babies: case-control study. BMF 1997;314:404-8.

37 Sutton L, Bajuk B, Duffy B, et al. Short-term outcome of mechanically ventilated infants weighing more than $2499 \mathrm{~g}$ at birth: a population based study. F Paediatr Child Health $1993 ; 29: 418-23$ 